Ethiopian Journal of Environmental Studies \& Management 9(6): 680 - 690, 2016.

ISSN:1998-0507

doi: http://dx.doi.org/10.4314/ejesm.v9i6.2

Submitted: February 04, 2016

Accepted: October 31, 2016

\title{
EMPIRICAL ANALYSIS OFEXTREME WEATHER CONDITIONS AND AVIATION SAFETY IN NIGERIA
}

\author{
AKANNI, C.0., *HASSAN, A.M. AND OSUJI, T.C. \\ Department of Geography, Faculty of Social and Management Sciences, Olabisi Onabanjo \\ University, Ago-Iwoye
}

\begin{abstract}
The frequency of delay, diversion and outright cancellation occasioned by poor weather has affected the Nigerian aviation industry and serious safety implication. This study therefore examines the influence of weather conditions on aviation safety in Nigeria. Secondary data basically from Nigeria Meteorological Agency such as information on thunderstorm, fog occurrence and rainfall from 2004 to 2013 and data obtained from Federal Airport Authority of Nigeria on air accident induced by extreme weather within the same period were analysed using Multiple Regression Analysis. Results show that low visibility as a result of fog occurrence causes four (4) air traffic accidents more than other weather conditions and that Lagos experienced two (2) air accidents more than other airports during the period under study. So also the value of $R^{2}$ shows a value of $77.8 \%$ which implies that there is variation in the dependent variable (Airport Operation) which can be predicted by independent variables (Weather conditions). The F-statistic value of 62.892 is also found to be statistically significant at $5 \%(p<0.05)$ which shows that weather condition has significant influence on aviation safety. Baseline studies on flight operation, government intervention in aviation industry, maintenance culture were recommended.
\end{abstract}

Key Words: Fog, Thunderstorm, Rainfall, Safety, Accident

\section{Introduction}

Transportation is an important aspect of human activities; the prosperity of a society can be traced to the efficiency of its transport sector. Abass and Ojo (2009) observed that the recent climate variation and change brought about by global warming is currently a concern to the aviation safety. Several airlines have been rendered moribund and some even made to be rendering partial services as a result of impacts of these extreme

*Corresponding Author: Hassan, A.M.

Email: simplygbayi@gmail.com weather events. Extreme weather and climate events have been classified into three categories- thermal, moisture and aerodynamic events (Ogunsanya, 2005). It is important to note that atmosphere which serves as a medium through which aircrafts fly is also the same medium (troposphere) in which weather occurs. Therefore, the knowledge and analysis of influence of extreme weather and climate change on air transport operation is imperative if safety is to be ensured in the 
industry. Climate change is a major global issue of common concern, affecting environment and development. Climate change is almost invariably considered an issue of global interest. The extent to which climate change represents a problem is still a highly debated issue. There has been an increasing awareness, concern and studies on weather as one of the causes of air disaster over the years. The importance of such studies cannot be overemphasized if air safety must be achieved. However, there is still low level of recognition and research attention on some weather parameters in Nigeria and in some cases weather is completely neglected. For instance Arizona-Ogwu (2008) in a study on safety of air transport in Nigeria reported that experts attributed the causes of air disaster to Pilot Error (human related), Pilot Error (weather related), Pilot Error (mechanical related), Other Human Error, Weather, Mechanical Failure, Sabotage plus Other Cause. Nevertheless, he attributed it to outdated Aircrafts being flown everywhere in Nigeria rather than what the experts revealed. Besides, between 1988 and 2005 (17 years), the private airlines recorded 12 crashes, of which only one had no casualties, while the total deaths recorded was 762. Also in 2008 , there was an increase of $4 \%$ in the number of fatalities against the preceding year, between 2009 and 2015, there was an increase of $153 \%$ fatalities in the nation's aviation industry in which over 209 people were involved (Hassan, 2015). Aderamo (2006) identified two factors that generally affect the operation of the aviation industry in Nigeria to include the human and the natural factors in a study, he reported that administrative, pilot's competence level, ground crew, type and model of aircrafts in use and condition of fuel used are human factors, while the natural factor includes weather condition such as cloud, temperature, fog, wind, precipitation, among others while Aderinto and Dahunsi (2008) opined that rainfall parameter was the most critical parameter influencing air transport services. Therefore, flight delay and cancellation becomes very frequent, serious and regular during the period of rainfall (March-October or early November) in Nigeria.

Adeyemi (2001), in his study shows that one of the greatest challenges in aviation safety in Nigeria is the weatherinduced aviation disasters. These types of disasters usually occur as result of wind shear, storms, and heavy rainfall. The study further revealed that wind shear, which is a hazardous meteorological phenomenon caused by sudden changes in the wind speed and, or direction over a short distance and, or short period, is particularly hazardous when it occurs at lower altitude. According to McGee (1982), Oberg (1996), Ortuzar and Wilumsen (2001), Herman et al. (2006), Dahunsi (2008), Anyadike et al. (2010) the concept of safe journey and weather forecast concept are two important concepts relevant to the study of aviation safety. It is important that passengers and goods must arrive safely without hurt and damage or delay. However, adequate weather forecast can be done and flight management can be controlled. Forecasting is needed to determine when an event will occur or a need arise, so that appropriate actions can be taken. 
Abubakar and Nurudeen (2011) also reported the cases of flight delay and cancellation because of poor visibility. They reported that flights from Kano, Abuja, Yola and other parts of the North especially, were delayed for 2 hours and above due to poor visibility. NIMET (2011) reported that the year 2010 witnessed a few instances of disruptions due to severe weather conditions. However, the month of March recorded a severe dust hazy spell, which reduced horizontal visibility to between $200 \mathrm{~m}$ $800 \mathrm{~m}$ for several days and this caused many disruptions in flight operations across the country. These disruption affected flight operations in Lagos, Abuja, Kano, Kaduna, Minna, Maiduguri, Sokoto, and Enugu. Others were Owerri, Port Harcourt and Calabar airports. There were also cases of outright cancellations. In January and December, early morning fog was reported in Lagos, Port Harcourt and Jos, which reduced horizontal visibility to between $200 \mathrm{~m}$ $800 \mathrm{~m}$. This resulted in flight delays at these airports. In addition, thousands of Europe-bound Nigerians were stranded at the Murtala Mohammed International Airport Lagos, as heavy snow pounded European airports in December. These harsh weather conditions affected the number of inbound and outbound flights at the Murtala Mohammed International Airport during the period. Various researchers have worked on the analysis of the relationship between weather and transport such as Abubakar and Nurudeen (2011); Abass and Ojo (2009) and Hermans et al., 2006), this study however fill the gap which exists in literatures by using an empirical analysis to justify the effect of the relationship which exists between aviation and weather conditions as it concerns safety.

\section{The Study Area}

The Nigerian Federal Government realizing the role of air transport in the nation's development made significant attempts to develop the country's air transport system. The most gigantic was the 1975-1980 Airport development programme in which the Murtala Mohammed airport complex was built (Filani, 1983). Six other airports in Kano, Ilorin, Kaduna, Sokoto, Port Harcourt and Maiduguri were developed to accommodate the largest intercontinental aircraft. According to Suleiman (2012), there are a total of thirty eight (38) airports with paved runways and sixteen (16) airports with unpaved runways which spread across 20 states in Nigeria as shown in Figure 1. Between 1980s and 1990s, many airports were built, existing ones were modernized and more services and facilities added, all under the management of Federal Airports Authority of Nigeria (FAAN).Total passenger traffic over the 2010-2013 period showed an overall increase, although this was not consistent over the period. In 2010, a total of $13,891,677$ passengers passed through Nigerian airports, increasing by 908,281 passengers or $6.50 \%$ in 2011 to reach $14,899,958$ passengers in that year. There was a drop in 2012 of $5.19 \%$ or 773,168 passengers to give a total of 14,116,790 passengers, a figure which was to grow again by 524,978passengers or $3.72 \%$ in 2013 , reaching $14,641,768$ passengers passing through Nigerian airports in this year (National Bureau of Statistics, 2014). 


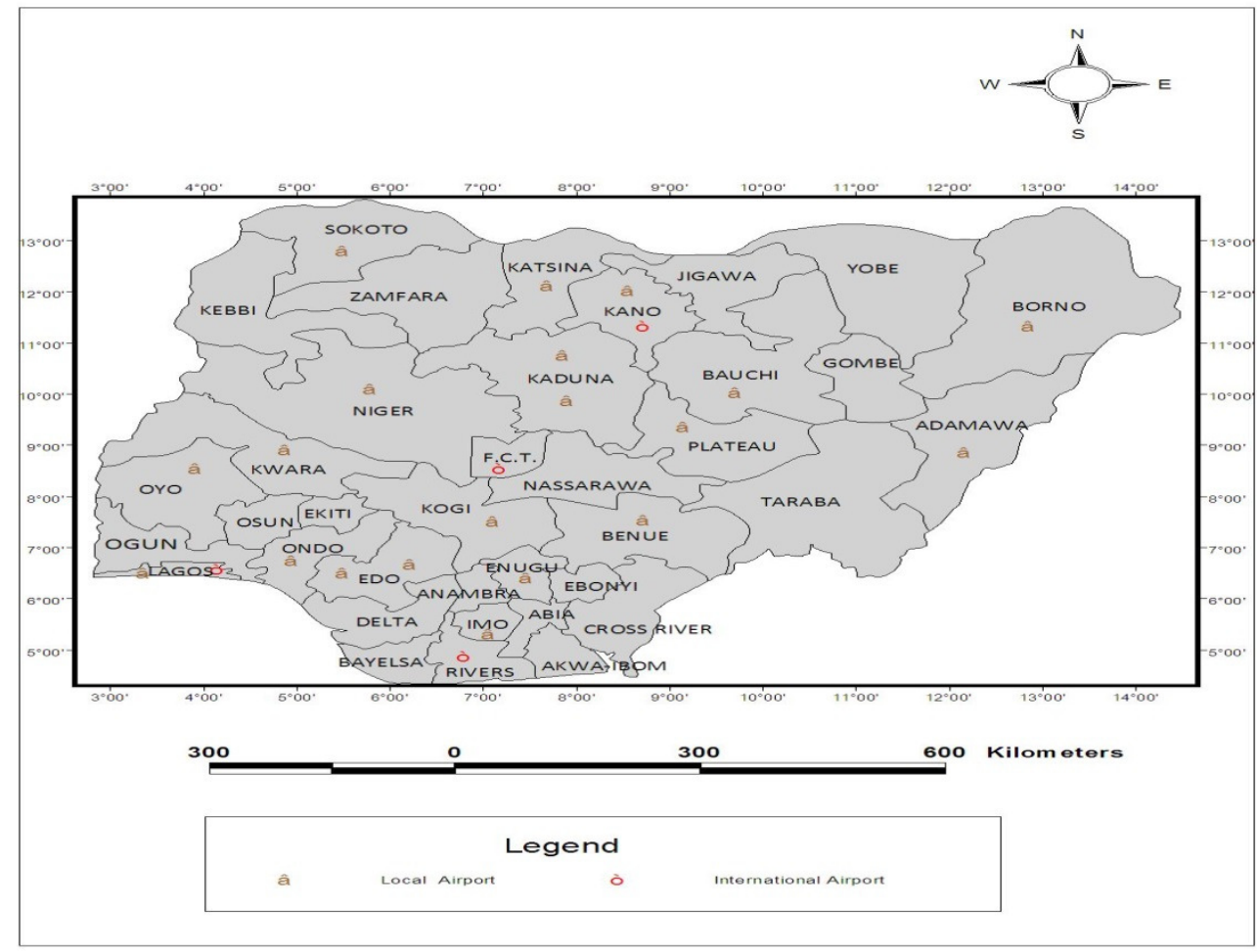

Figure 1: Map of Nigeria Showing the Locations of Domestic and International Airports

\section{Methodology}

Data for this study are basically secondary data which include collection of data on air crashes induced by extreme weather, weather conditions within the periods which include thunderstorm, fog occurrence and Rainfall collected from Nigeria Meteorological Agency and weather induced accident in Nigeria collected from Federal Aviation Authority of Nigeria over a period of ten years (2004-2013). Multiple Regression Analysis was used to analysed the effect of weather on Air Transport in Nigeria. In order to determine multiple regression model for the study, a regression model was developed using airport operation i.e. air transport patronage from 2004 to 2013 as dependent variable (y) and the influence of weather conditions at the airport such as fog occurrence, rainfall, thunderstorm as independent variables $\left(\mathrm{x}_{1}, \mathrm{x}_{2}, \mathrm{x}_{3}\right)$ so as to determine the overall contribution of these parameters in the multiple regression equation to airport operation in Nigeria.

\section{Results and Discussion}

Despite the relatively conducive weather of Nigeria compared to other countries (Such as Mauritania, Somalia and Japan), there has been a recorded period of air crashes occurrence. This study examines the occurrence of air crashes caused by weather. Analysis shows that adverse weather condition caused eight (8) air crashes in Nigeria between 2004 and 2013 as shown in Table 1. Low visibility and Thunderstorm caused two air crashes in Nigeria in the year 2004. The former occurred in Bauchi March 16, 2004 caused by low 
visibility while the later occurred in Delta State involving a Helicopter owned by Pan African which crashed into the Atlantic Ocean due to thunderstorm. In 2005, 4 weather induced air crashes occurred caused by low visibility and high temperature. Remarkably, from 2006 to 2013 no air crash was recorded due to adverse weather.

Table1: Pattern of Weather Induced Air Crashes in Nigeria

\begin{tabular}{llllll}
\hline S/N & AIRCRAFT & DATE & YEAR & LOCATION & WEATHER CAUSE \\
\hline 1 & 5NBEF & March 6 & 2004 & Bauchi & Low Visibility \\
2 & $\begin{array}{l}\text { Pan African } \\
\text { Delta State }\end{array}$ & Thunderstorm \\
& Helicoper & & 2004 & & \\
3 & B73 & February 25 & 2005 & Yola & High Temperature \\
4 & Boeing 727 & June 11 & 2005 & Lagos & Visibility \\
5 & Boeing 200 & June 12 & 2005 & Jos & Low Visibility \\
6 & Airbus A330 & July 6 & 2005 & Porthacourt & Low Visibility \\
7 & Boeing 737 & October 29 & 2006 & Abuja & Rain Storm \\
8 & 5N-BJY & October 3 & 2013 & Lagos & Low Visibility \\
\hline
\end{tabular}

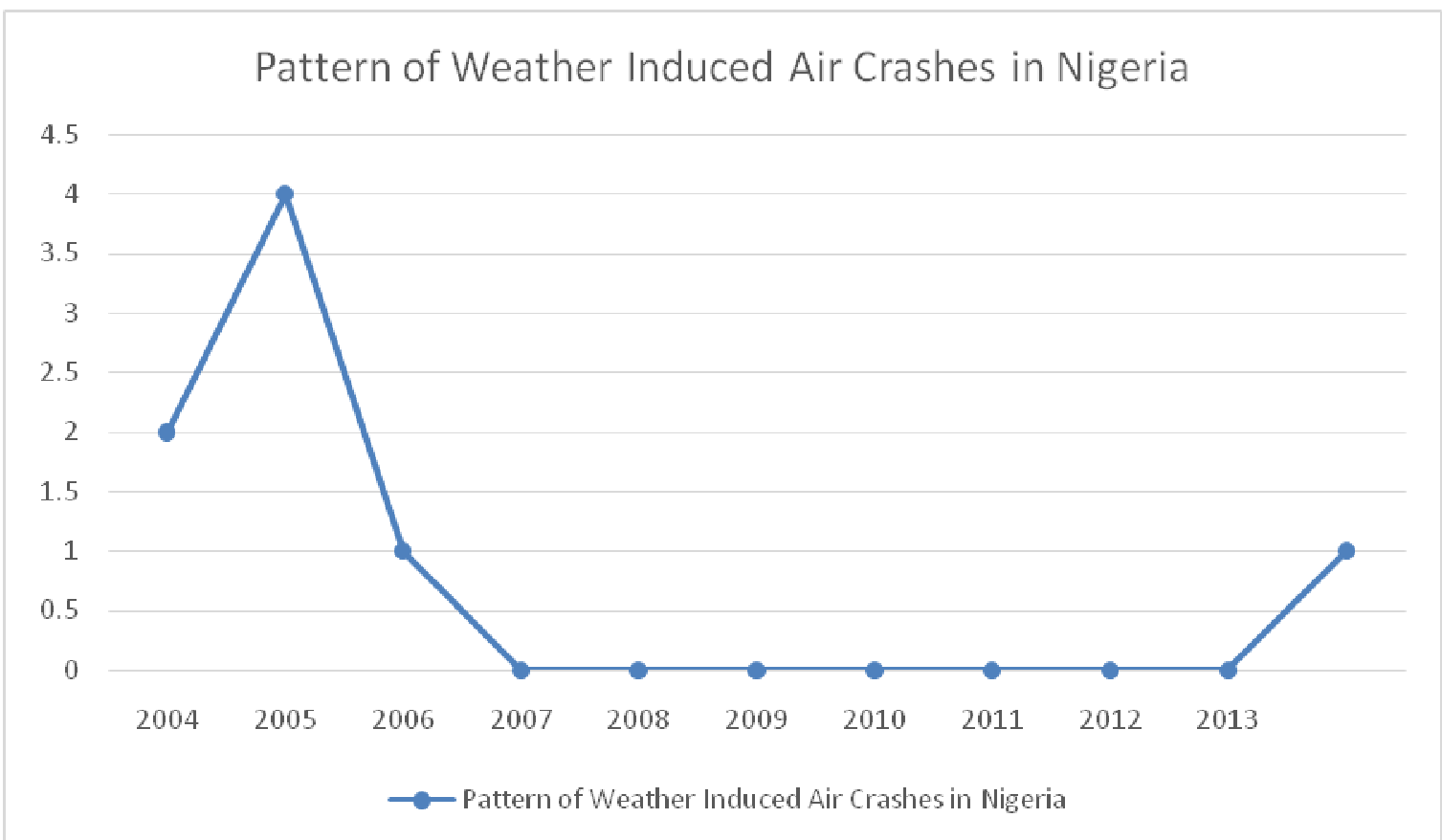

Figure 2: Pattern of Weather Induced Air Crashes in Nigeria

Adverse weather affects air transportation in various ways ranging from flight delay, cancellation and if not well managed can as well leads to air crashes. In Nigeria, extreme weather parameters have caused many air crashes.
This study adopted four weather parameters; Thunderstorm, Fog Occurrence which result to low visibility, and rainfall. Analysis shows that Low visibility and Fog occurrence amount to the substantial number of weather 
induced accident in Nigeria within the period of 2004 and 2013. Rainfall and Thunderstorm also contributed to air crashes in 2004 and 2006 respectively. The analysis is further shown in table 2 below.

Table 2: Distribution of Weather Induced Air Crashes

\begin{tabular}{lccccc}
\hline YEAR & LOW & THUNDERSTORM & FOG & RAIN FALL & TOTAL \\
& VISIBILITY & & OCCURRENCE & & \\
\hline 2004 & 1 & 1 & - & - & 2 \\
2005 & 2 & - & - & - & 3 \\
2006 & - & - & - & - & 1 \\
2007 & - & - & - & - & - \\
2008 & - & - & - & - & - \\
2009 & - & - & - & - & - \\
2010 & - & - & 1 & - & - \\
2011 & - & - & - & - & 1 \\
2012 & - & - & 2 & 1 & 1 \\
2013 & 1 & - & &
\end{tabular}

\section{Rainfall}

Analysis of Rainfall within the period of 2004 and 2013 shows that the average rainfall fluctuates momentarily within this time period. In 2006, the highest period of rainfall with average rainfall of 180.97 occurs while the lowest rainfall occurs in 2007 with Total average of $126.6 \mathrm{~mm}$. June has the highest number of rainfall while the lowest rainfall falls in December. With the high rainfall, only one air crash was recorded in October 2006.

Table 3: Rainfall Distribution in the Study Area

\begin{tabular}{llllllllllllll}
\hline & Jan. & Feb. & Mar. & April & May & June & July & Aug. & Sept. & Oct. & Nov. & Dec. & Ave. \\
\hline & Mm & $\mathrm{mm}$ & $\mathrm{mm}$ & $\mathrm{Mm}$ & $\mathrm{Mm}$ & $\mathrm{mm}$ & $\mathrm{mm}$ & $\mathrm{Mm}$ & $\mathrm{mm}$ & $\mathrm{mm}$ & $\mathrm{Mm}$ & $\mathrm{Mm}$ & $\mathrm{mm}$ \\
\hline 2004 & 6.4 & 45.5 & 122.8 & 291.1 & 306.1 & 213.5 & 94.5 & 68.5 & 321.2 & 160.9 & 50.0 & 20.5 & 141.3 \\
2005 & 91.7 & 93.1 & 78.2 & 94.1 & 185.3 & 392.3 & 225.3 & 15.0 & 194.2 & 94.8 & 96.4 & 16.2 & 131.38 \\
2006 & 44.2 & 10.7 & 121.8 & 26.4 & 294.3 & 264.0 & 52.8 & 65.7 & 327.6 & 191.3 & 95.3 & 4.6 & 180.97 \\
2007 & 0.0 & 0.0 & 76.1 & 31.6 & 253.7 & 367.7 & 228.0 & 146.1 & 160.1 & 120.3 & 118.3 & 5.4 & 126.6 \\
2008 & 0.08 & 3.3 & 69.6 & 96.8 & 230.0 & 365.0 & 442.7 & 134.3 & 226.8 & 98.9 & 98.9 & 49.0 & 151.28 \\
2009 & 1.6 & 16.3 & 33.9 & 115.5 & 154.2 & 463.4 & 119.0 & 12.0 & 84.1 & 342.7 & 48.7 & 0.0 & 115.95 \\
2010 & 37.2 & 42.4 & 68.0 & 126.9 & 159.3 & 368.7 & 130.8 & 190.6 & 235.7 & 122.8 & 193.8 & 76.7 & 146.07 \\
2011 & 0.0 & 87.2 & 21.6 & 74.7 & 170.6 & 251.9 & 476.9 & 43.7 & 175.3 & 209.8 & 240.5 & 0.0 & 146.01 \\
2012 & 10.5 & 122.2 & 78.1 & 124.7 & 134.9 & 478.8 & 152.1 & 34.3 & 214.1 & 148.9 & 123.2 & 0.0 & 135.1 \\
2013 & 133.7 & 34.7 & 121.8 & 202.3 & 339.4 & 108.0 & 190.8 & 12.6 & 165.3 & 125.6 & 249.9 & 47.9 & 144.33 \\
Total & 32.5 & 45.5 & 79.1 & 118.4 & 222.8 & 327.3 & 211.3 & 72.28 & 210.4 & 161.6 & 131.5 & 22.03 & \\
\hline
\end{tabular}




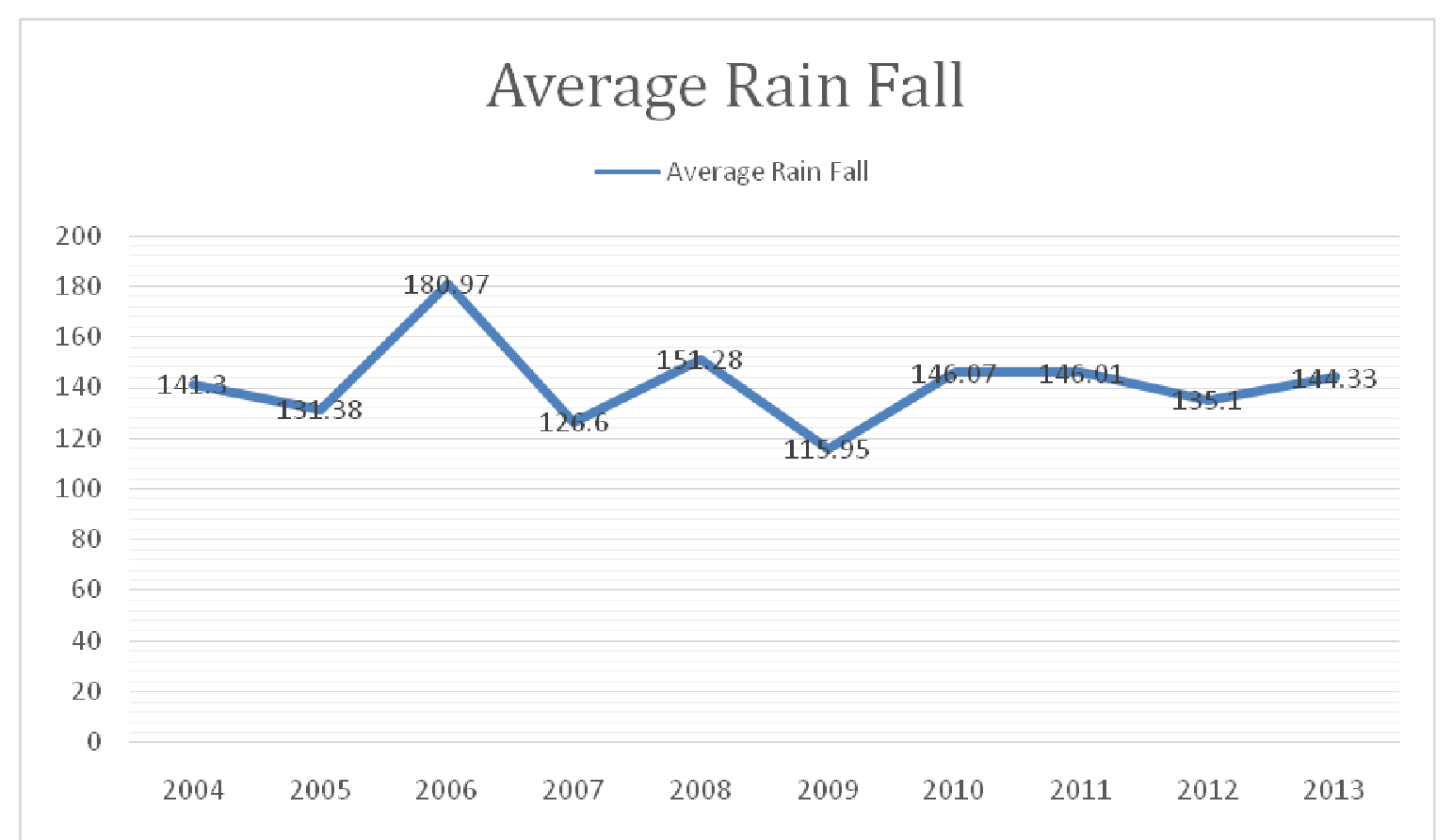

Figure 3: Rainfall Distribution in the Study Area

\section{Fog Occurrence}

Analysis of fog occurrence shows that fog occurrence happens mostly in 2004 and was reduced in 2005 with further reduction in 2006. But in 2007, fog occurrence increased slightly and reduced drastically in 2008 but increase in 2009 and as well as 2010 but fell in 2011 then increase in 2012. However, most of the fog occurrence happens in appear mostly in October, November and become heavy in December; having the highest record, and January during the Harmattan season. In relation to safety, fog occurrence has been the result of 2 accidents between 2004 and 2013. Fog occurrence decreases visibility which determines the length at which a pilot can see ahead. Fog can result to accident if not well managed. 


\section{Distribution of Fog Occurrence in the Study Area}

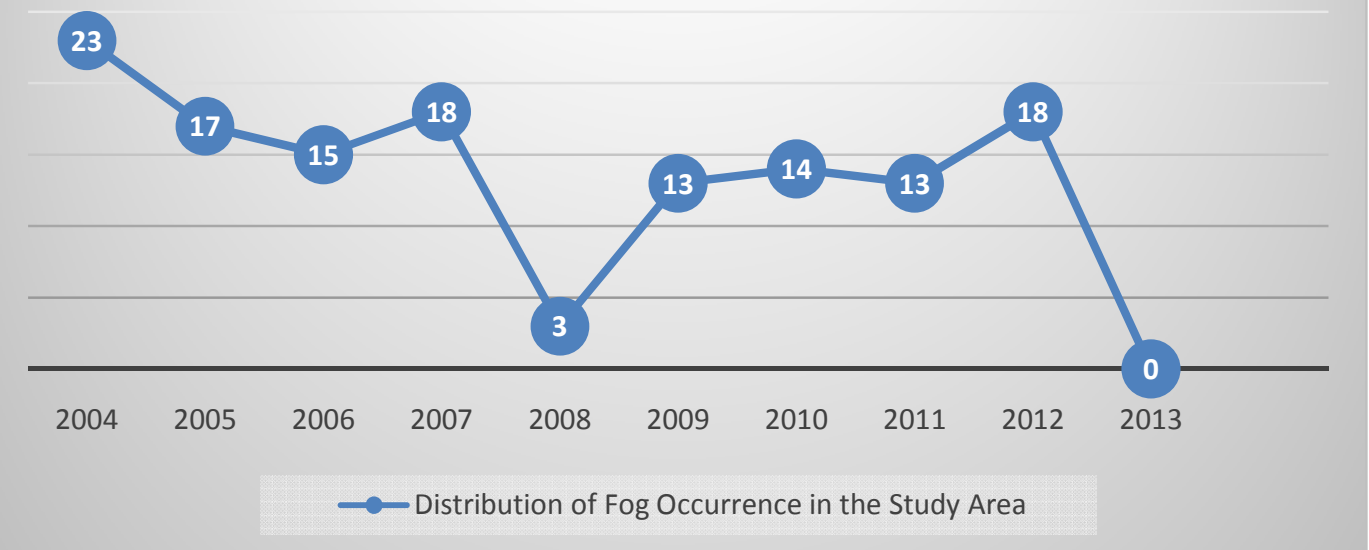

Figure 4: Distribution of Fog Occurrence in the Study Area

\section{Thunderstorm Occurrence}

Thunderstorm occurrence in Nigeria shows that June has the highest rate of thunderstorm occurrence from 2004 to 2013 with 173 event of thunderstorm in Lagos State. The occurrence of which is predominantly in year 2008. However, the occurrence of thunderstorm is very low in January and December. Year 2005 recorded the lowest occurrence of thunderstorm. The lowest occurrence of thunderstorm happens in August while
June recorded the highest rate of thunderstorm Aviation safety is high within the period of less thunderstorm and low in period of high thunderstorm. In relation to occurrence of air traffic accident, it has not being able to cause more havoc due to aviation and weather management. The only air crashes recorded within the period of study caused by thunderstorm happens in July, 2004.

Table 4: Distribution of Thunderstorm Occurrence

\begin{tabular}{llllllllllllll}
\hline & Jan. & Feb. & March & April & May & June & July & Aug. & Sept. & Oct. & Nov. & Dec. & Total \\
\hline 2004 & 2 & 4 & 4 & 9 & 13 & 12 & 4 & 2 & 11 & 19 & 9 & 1 & 90 \\
2005 & 1 & 2 & 11 & 11 & 12 & 15 & 6 & - & 5 & - & 6 & - & 69 \\
2006 & 4 & 4 & 8 & 11 & 14 & 15 & 3 & - & 6 & 12 & 5 & 1 & 93 \\
2007 & - & 2 & 3 & 14 & 131 & 15 & 5 & 6 & 8 & 13 & 12 & - & 91 \\
2008 & 2 & 1 & 8 & 8 & 17 & 16 & 14 & 5 & 10 & 14 & 15 & 3 & 113 \\
2009 & 2 & 8 & 10 & 10 & 13 & 22 & 7 & - & 6 & 16 & 6 & 1 & 100 \\
2010 & 3 & 6 & 6 & 10 & 10 & 16 & 6 & 5 & 8 & 16 & 12 & 7 & 98 \\
2011 & - & 8 & 4 & 7 & 12 & 18 & 8 & 4 & 8 & 17 & 13 & - & 99 \\
2012 & 1 & 10 & 8 & 12 & 15 & 20 & 5 & 1 & 7 & 15 & 16 & 2 & 112 \\
2013 & 4 & 2 & - & 23 & 18 & 24 & 14 & 6 & - & 15 & - & 5 & 111 \\
Total & 19 & 47 & 62 & 115 & 125 & 173 & 72 & 29 & 101 & 137 & 94 & 20 & 999 \\
\hline
\end{tabular}

Source: Nigeria Meteorological Agency, 2015 


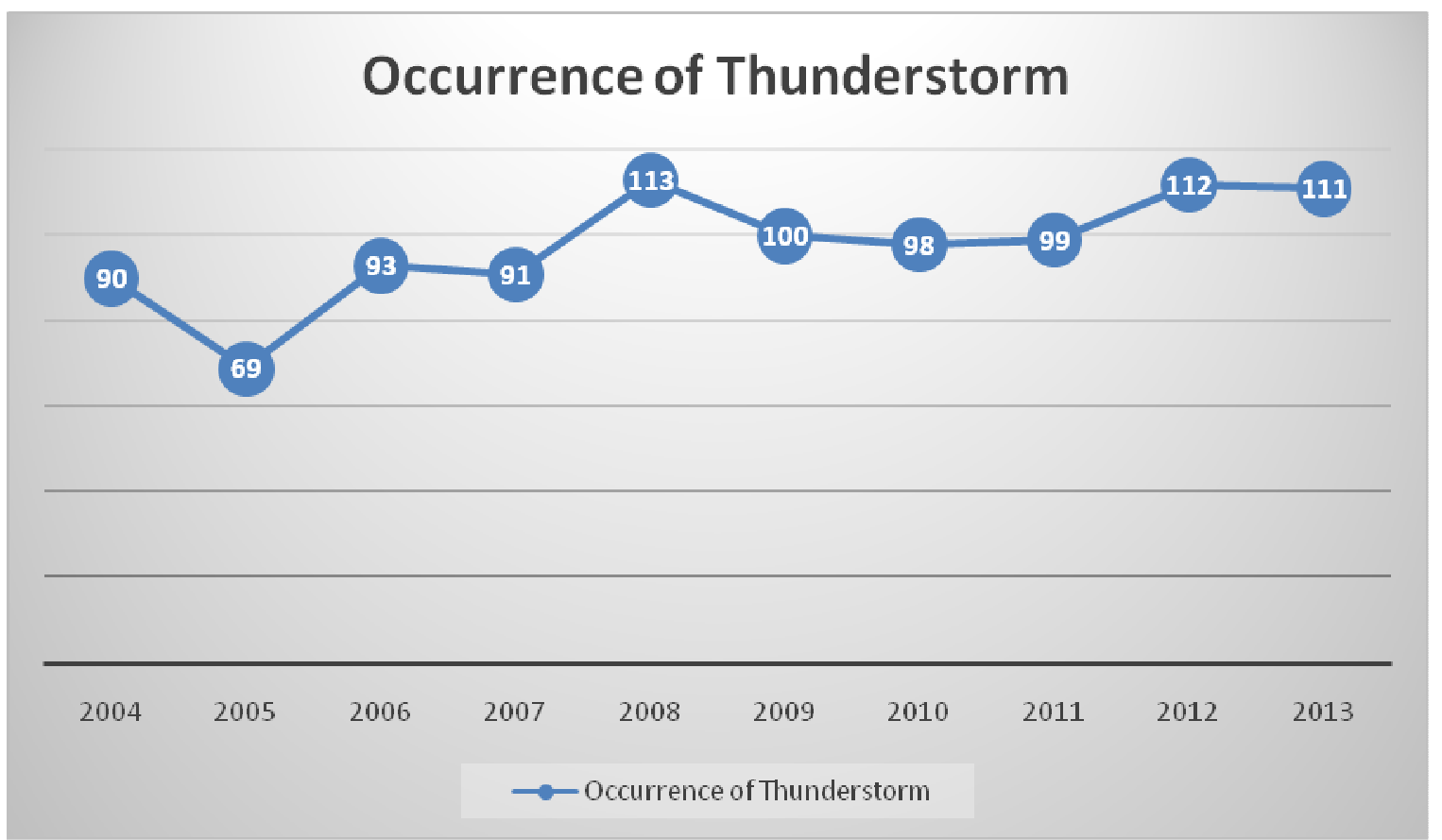

Figure 5: Distribution of Thunderstorm Occurrence

Table 5: Multiple Regression Result Showing Significant Impact of Weather on Air transport

\begin{tabular}{|l|l|l|l|l|}
\hline Explanatory & $\alpha$ coefficient & Standard Error & t- statistic & Prob \\
\hline Constant & 0.589 & 4.837 & 4.929 & 0.0000 \\
\hline Restriction policy & 0.438 & 2.893 & 2.093 & 0.0000 \\
\hline
\end{tabular}

$\mathrm{R}^{2}=77.8 \%$, Adj $\mathrm{R}^{2}=79.2 \%, \mathrm{~F}=62.892$

The result reveals that Weather condition explains the variation in Air Transport. The value of $\mathrm{R}^{2}$ which shows a value of $77.8 \%$ implies that the variation in the dependent variable (Air Transport) can be predicted by 77.8 percent from the exogenous or independent variable (Weather condition). The average of weather condition $(\alpha=0.438)$ is significant at ( $\mathrm{p}=0.000$ ), and the coefficient is positive meaning that the higher the degree of $\mathrm{bad} /$ good weather the higher the effect on air transport. The F-statistic value of 62.892 is found to be statistically significant at $5 \%(\mathrm{p}<0.05)$. The above result shows that Weather condition has significant influence on Air Transport.

\section{Recommendation and Conclusion}

The effective monitoring and control of fog are relevant for the effective management of air transport hazards in Nigerian airports especially Murtala Mohammed Airport, Lagos. This will reduce the rate at which flights are delayed, diverted, cancelled and subsequent accidents arising from diversion resulting from meteorological phenomena. The intervention of government in the aviation industry as some of the equipment used there are already outdated. These obsolete 
Empirical Analysis of extreme Weather Conditions and Aviation Safety..................KANNI et al.

equipment can only perform six hours weather update and can be replaced with those that update weather conditions every hour. There is need for baseline studies on flight operations with a view to raising data for more researches. Security bottleneck on data acquisitions in the aviation industry should be relaxed to give room for more researches.

The aviation bodies concerned with safety rules should ensure the accuracy of weather reports and strict compliance to weather reports and safety regulations to avoid or minimize air disaster. Since it was reported that Nigerian Pilots often ignored weather reports and safety rules in a bid to make more money, as they are paid according to the number of flights and hours they logged.

The laisser-faire attitude to aviation regulation in Nigerian Airspace by aircraft operators and airlines should be sanctions and prosecuted by appropriate authority or regulatory body. Refresher courses for personnel is a powerful and effective tool in air disaster management and should be enforced for aviators particularly Pilots and Air Traffic Controllers for effective management of weather, technical and economic reports to mitigate problems encountered by Pilots on landing and takeoff phases of aircraft flight. Maintenance culture should be imbibed by all and sundry in the aviation industry to ensure the up to date function of the state of the art equipment in the airports and to mitigate the problems of mechanical failures of aircraft, bad fuel condition (contamination), and outdated aircrafts. The need to accurately understand the trends and causes of air disasters is very important towards eliminating, if not, minimizing the risk of air disasters in
Nigerian Airspace. Most of the causes of air disasters are within rational ability to mitigate if the right attention is given. Finally, government should embark on massive employment and training of staff in the aviation sector to drastically reduce the effects of overburden and human error in weather observation and reporting while the staff of the aviation industry should see their job as that on which people's lives depend as any mistakes they make results in loss of lives and property.

\section{References}

Abass, S.U. and Ojo, A.J. (2009). Air Transportation in Nigeria: Past, Present Lessons and Challenges for the Aviation Industry. Journal of Geography and Planning Sciences, 1(1): 145-164.

Abubakar, S. and Nurudeen, N.A. (2011). Nigeria Bad Weather Causes Flight Delays, Cancellation. Retrieved from Daily Trust, the online edition January, 2011 from allafrica.com

Aderamo, A.J. (2006). Changing pattern of Air Traffic in Nigeria. Nigerian Journal of Management and Social Sciences, 3 (1): 77-89.

Aderinto, S. and Dahunsi, I. (2008). The New Automated Meteorological Observation at Four Airports in Nigeria. Abuja. Retrieved September 13, 2009 from www.wmo.int/pages/prog/www/IM OP/publications/10M96_TECO200 8/P2(32)_Aderinto_Nigeria.doc Adeyemi, O. (2001). Moving Nigeria Forward: The Development Planning Approach. Ibadan: Ibadan University Press.

Anyadike, R.N.C., Madu, I.A. and Ajaero, C. K. (ed.). (2010). Climate 
Change and the Nigerian Environment. A Conference Proceedings. Nsukka: Department of Geography, University of Nigeria, pp. 454-455.

Arizona-Ogwu, L.C. (2008). Air Transport. Enticing Our Citizens into Suicide Mission. Nigeria World Features Articles.

Filani, M.O. (1983) .Air Transportation in Oguntoyinbo, J.S., Areola, O.O., Filani M. eds. A Geography of Nigerian Development. Second edition, Heinemann Education (Nigeria) Ltd.

Hermans, E., Brijs, T., Stiers, T. and Offermans, C. (2006). The Impact of Weather Conditions on Road Safety Investigated on an Hourly Basis, Transportation Research Board Annual Meeting 2006, CDROM Paper 06-1120. Hogema JH, 1996, Effects of Rain on Daily Traffic Volume and on Driving Behaviour, TNO-report TM-96B019, TNO Human Factors Research Institute, Soesterberg.

Hassan, A.M. (2015). Analysis of Emergency Response Procedures and Air Traffic Accidents in Nigeria. Ethiopia Journal of Environmental Studies and Management, 8(6): 662-668. ISSN 1998-0507.

National Bureau of Statistics (2014) "Nigeria Aviation Sector, Summary report of passenger traffic: 2010-2013 and Q1, 2014.

Ogunsanya, A.A. (2005). Emergence and Development of Aviation Industry and the Role of the Transportation sector in Nigerian Economy. Paper presented at the Training Workshop for officials of Nigerian Airspace Management agency (NAMA) at Michael Imoudu Institute for Labour Studies, Ilorin.

Ortúzar, J., de D, L. and Willumsen, G. (2001). Modelling Transport, Third Edition, John Wiley \& Sons, Ltd, West Sussex, England.

Suleiman, I.L. (2012). "Analysis of air Transport in Nigeria" JORIND 10 (2), June, 2012. ISSN 1596 8308.

www.transcampus.org./journals, www.ajol.info/journals/jorind. pp230-237 